\title{
PRODUÇÃO BIOTECNOLÓGICA DE PRODUTOS DE VALOR AGREGADO UTILIZANDO GLICEROL RESIDUAL PROVENIENTE DA SÍNTESE DE BIODIESEL
}

\author{
Silva $\mathrm{DB}^{*}$, Souza BR ${ }^{* *}$, Antero RVP ${ }^{* * *}$
}

\begin{abstract}
Resumo
O aumento significativo na produção de biodiesel por transesterificação de óleos comestíveis e não comestíveis causaram excedente de glicerol no mercado. Com suas características, estrutura química única, renovabilidade e biodisponibilidade, o glicerol tem promissor potencial para ser transformado em produtos químicos de alto valor agregado. Este artigo oferece uma análise abrangente e crítica do tratamento biotecnológico do glicerol a 1,3-propanodiol e 2,3-butanodiol. A conversão microbiana do glicerol apresenta vantagens em relação às sínteses químicas requerendo menor número de etapas, temperaturas medianas e pressão do ambiente, além de não gerar intermediários tóxicos.

Palavras-chave: Micro-organismos. Biodiesel. Transesterificação. Fermentação de glicerol.
\end{abstract}

\footnotetext{
* Mestre em Biotecnologia pela Universidade Federal do Tocantins; Pós-graduada em Gestão Ambiental pela Faculdade de Ciências Sociais e Aplicadas de Marabá; doutoranda em Tecnologias Química e Biológica pela Universidade de Brasília; damisb@gmail.com ** Mestre em Ciências Florestais pela Universidade de Brasília; Pós-graduado em Gestão e Manejo Ambiental na Agroindústria pela Universidade Federal de Lavras; doutorando em Tecnologias Química e Biológica pela Universidade de Brasília; brsvzp@hotmail.com *** Mestre em Tecnologia de Processos Sustentáveis pelo Instituto Federal de Goiás; doutorando em Tecnologias Química e Biológica pela Universidade de Brasília; victor.halle@yahoo.com.br
} 


\section{Biotechnological production of value-added products using residual glycerol from synthesis of biodiesel}

\section{Abstract}

The significant increase in the production of biodiesel by transesterification of oils edible or inedible caused of glycerol surplus in the market. With its features, unique chemical structure, renewability, bio-availability, glycerol has promising potential to be turned into chemicals with high added value. This article provides a comprehensive review and critique of biotechnological treatment of glycerol to 1,3-propanediol and 2,3-butanediol. The microbial conversion of glycerol has advantages over chemical syntheses require fewer steps, medians temperatures, ambient pressure plus not generate toxic intermediates.

Keywords: Microorganisms. Biodisel. Transesterification. Fermentation of glycerol.

\section{INTRODUÇÃO}

A rápida industrialização e a diminuição do estoque de petróleo aumentaram consideravelmente a necessidade mundial de geração de energia a partir de recursos alternativos e renováveis, como por exemplo, o biodiesel, o biohidrogênio e o bioetanol, considerando-se o biodiesel uma das fontes de energia renováveis mais importantes. ${ }^{1}$ Tradicionalmente preparado por meio de processos de transesterificação química ou enzimática de gorduras vegetais ou animais com álcoois de cadeia curta, a síntese do biodiesel está diretamente relacionada à alta produção de glicerol residual, também conhecido como glicerina bruta ou glicerol brutos). ${ }^{2} \mathrm{Na}$ última década, a demanda contínua de biocombustíveis alternativos levou a um aumento significativo na produção de biodiesel e, consequentemente, na produção do seu subproduto, o glicerol. Para cada $10 \mathrm{~kg}$ de biodiesel produzidos, $1 \mathrm{~kg}$ de glicerol fica disponível; como consequência, grandes quantidades de glicerol bruto foram acumuladas, levando, portanto, a uma queda considerável no seu preço de mercado. ${ }^{3}$

Considerando a enormidade do contingente de glicerol residual gerado nos últimos anos, a conversão dessa abundante fonte de carbono em produtos de valor agregado por meio de tecnologia microbiana consiste em uma oportunidade significativa para a biotecnologia industrial atual. Nesse aspecto, um número crescente de pesquisas tem demonstrado a bioconversão do glicerol bruto em 1,3-propanodiol (PD) mediante fermentação microbiana. Esse composto é amplamente empregado como monômero para a síntese de tereftalato de politrimetileno, além de diversos outros poliésteres com propriedades importantes e úteis para a indústria de plásticos, fibras e têxteis, além de poder ser empregado em uma variedade de outros produtos, incluindo cosméticos, produção de medicamentos, lubrificantes, etc. ${ }^{4}$

Além do 1,3-propanodiol (PD), a conversão biotecnológica do glicerol residual em 2,3-butanodiol (BD) também vem sendo alvo de inúmeras pesquisas. $\mathrm{O}$ BD trata-se de um composto químico com grande importância para a indústria de combustíveis, apresentando um calor de combustão supe- 
rior ao etanol. ${ }^{1}$ Somando-se a essa propriedade, o 2,3-butanodiol também é amplamente empregado como precursor para a produção de borracha sintética, plásticos, realçante de sabor, etc. Comparado com a rota química, a produção biológica de 2,3-butanodiol é descrita como mais barata em razão dos seus processos menos intensivos em energia com micro-organismos. ${ }^{5}$ Assim, o 2,3-butanodiol é considerado um produto promissor na indústria bioquímica, e sua obtenção a partir do glicerol residual é apontada como uma nova estratégia para as biorrefinarias.

O biodiesel não contém aromáticos, mas contém ésteres metílicos com diferentes níveis de saturação. Ésteres insaturados têm baixo conteúdo energético, mas sua alta densidade proporciona mais energia por unidade de volume. ${ }^{6}$

Em relação à matéria-prima para a produção de biodiesel produzido, 28\% dos países usam óleo de soja, $22 \%$ óleo de palma, $20 \%$ gorduras animais, $11 \%$ óleo de coco e $5 \%$ utilizam óleo de canola, girassol ou azeite. ${ }^{7}$ Todas essas matérias-primas são comestíveis, competindo com o consumo humano de alimentos. Em atendimento a essa perspectiva, pesquisas têm sido realizadas para utilização de matérias-primas alternativas, especificamente fontes vegetais e microbianas não comestíveis e reuso de óleos, além disso um conjunto de potenciais fontes pode ser necessário para atender às demandas de biodiesel mantendo o equilíbrio ambiental na consolidação ou no desenvolvimento de processo versátil e robusto capaz de processar ampla gama de matérias-primas. ${ }^{8}$

O glicerol residual possui contaminantes, como metanol, catalizador, sabão e glicerídeos, tornando-o impróprio para o mercado consumidor sem os processos de purificação, que geram aumento nos custos. Nesse contexto, diversos processos eficientes em termos energéticos (combustão, compostagem, digestão anaeróbia ou conversões biológicas) podem ser utilizados para aproveitamento do glicerol e produtos líquidos valiosos como etanol, butanol e 1,3-propanodiol. ${ }^{9}$

O custo da produção de biodiesel é altamente dependente do preço do glicerol, constituindo-se um desafio integrar a fermentação do glicerol dentro das instalações de produção de biodiesel, otimizando, assim, a viabilidade do reaproveitamento. Mesmo produzindo etanol a partir do glicerol, o resíduo de metanol no glicerol tende a complicar os processos que produzam simultaneamente bioetanol e biodiesel. ${ }^{10}$

A eficiência da conversão de biodiesel por meio da transesterificação depende da natureza da matéria-prima, tipo e quantidade do álcool e catalizador, temperatura de operação e tempo de reação. ${ }^{11}$ No presente trabalho tem-se como objetivo analisar criticamente as atuais conjecturas da produção de glicerol e suas projeções no que se refere à minimização de resíduos, fomentando o reuso na concepção de plantas produtivas que visem à cogeração de produtos com alto valor agregado.

\section{BIODIESEL E PROCESSOS DE TRANSESTERIFICAÇÃO}

Vários procedimentos são capazes de converter óleos vegetais em combustíveis que apresentam propriedades semelhantes ou comparáveis ao diesel. A transesterificação, o craqueamento, a microemulsificação e a pirólise estão inclusos nessa classificação. ${ }^{12}$ Entre esses, o processo de transes- 
terificação ou alcoolize, em razão da sua versatilidade, tem sido empregado em diversos processos industriais, sendo explorado há anos na produção de biodiesel. De maneira simples e bem estabelecida, a técnica engloba uma reação na qual um álcool primário reage com os triglicerídeos de ácidos graxos (óleo vegetal) na presença de um catalisador para formar glicerol e ésteres.

A produção de biodiesel por transesterificação é descrita em numerosos artigos científicos; geralmente ela pode ser realizada por catálise ácida, básica, entre outras, no entanto, em catálise homogênea, catalisadores alcalinos, como hidróxido de sódio e de potássio, geram processos mais rápidos. ${ }^{6}$ Independentemente do processo catalítico, na transesterificação o triglicerídeo é convertido em diglicerídeo, e este é convertido em monoglicerídeo ou éster metilo, nomeado como biodiesel. O álcool reage com óleo vegetal na presença de um catalizador, e o fluido é convertido em biodiesel e glicerina (glicerol) como descrito na Figura 1.

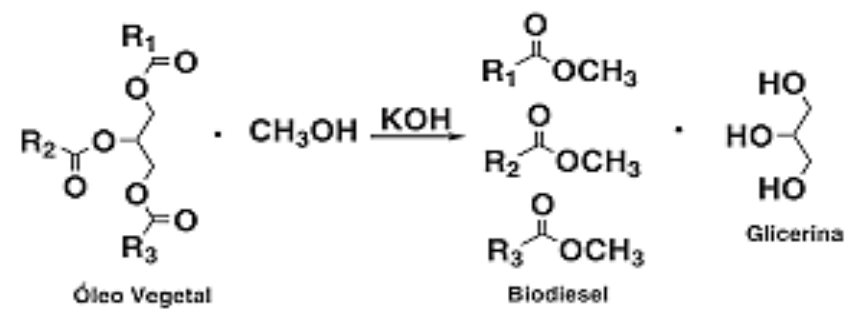

Figura 1 - Reação de Transesterificação

Fonte: Knothe, van Gerpen, Krahl e Ramos. ${ }^{6}$

Geralmente, o efeito de variáveis operacionais na reação de transesterificação é determinante nas propriedades do combustível biodiesel produzido, como o catalisador, a influência da concentração de metanol, bem como da temperatura de operação. ${ }^{13}$

A transesterificação de triglicerídeos utilizando metanol na presença de um catalisador alcalino é o processo mais comum para a produção de biodiesel, entretanto, o etanol pode ser usado como substituto para o metanol na reação de transesterificação, podendo ser utilizado como combustível alternativo. O metanol é mais barato, porém o óleo é menos solúvel nele, e a metanólise envolve a transferência de massa limitada durante a transesterificação. O uso de etanol é mais seguro, tem mais solubilidade em óleo, além do cunho renovável. O etanol é obtido da fermentação de biomassa renovável, enquanto o metanol é produzido industrialmente a partir de fontes de combustíveis fósseis. ${ }^{14}$

\section{GLICEROL}

O glicerol puro pode apresentar inúmeras aplicações na fabricação de cosméticos, tintas, alimentos, fármacos, papel e celulose, couro, têxteis e revestimento para barcos. Os resíduos enriquecidos com glicerol da produção de biodiesel têm purificação inviável pelo alto custo, e sua eliminação é ecologicamente incorreta. Nesse aspecto, a forma mais comum de valorização biotecnológica de 
glicerol refere-se à sua conversão em 1,3-propanodiol. Além desta, o glicerol bruto pode ser aplicado como substrato para a produção de outros metabólicos, como ácidos orgânicos, polióis, lipídios microbianos, carotenoides 2,3-butanodiol e butanol. ${ }^{7}$

O produto final da reação da transesterificação se divide basicamente em duas partes: glicerol livre e glicerol ligado, sendo este último uma mistura de pequenas quantidades de tri-di-e monoglicerídeos. Quando o glicerol livre é somado ao glicerol ligado é conhecido como glicerol total. ${ }^{6}$

O bioetanol é um combustível limpo, renovável produzido a partir de matérias-primas de baixo custo. Em pesquisa realizada, obteve-se 11,1 g/L de etanol a partir da fermentação de $45 \mathrm{~g} / \mathrm{L}$ de glicerol utilizando micro-organismos (Enterobacter e Klebisiela), porém parte do rendimento foi comprometido nos processos de purificação. Outra limitação é o controle efetivo do $\mathrm{pH}$, porém o uso de glicerol como fonte na obtenção de etanol reduziu os custos de produção em $40 \% .{ }^{15}$

A partir de um organismo único Escherichia coli SS1, produziram-se 0,57 mol de hidrogênio e 0,88 mol de etanol para cada mol de glicerol, simultaneamente. ${ }^{16}$ Essa cepa microbiológica apresentou desempenho 50\% maior do que outras cepas de referência, porém produziu dois combustíveis simultaneamente.

\section{FERMENTAÇÃO DO GLICEROL}

O glicerol $\left(\mathrm{C}_{3} \mathrm{H}_{8} \mathrm{O}_{3}\right)$ pode ser fermentado por Escherichia coli e é detectado entre os produtos finais $\mathrm{H}_{2}, \mathrm{CO}_{2}$, etanol, acetato, etc. Durante o processo fermentativo, o $\mathrm{pH}$ é ligeiramente ácido $(\mathrm{pH}=$ 6,3), e as vias de fermentação do glicerol dentro da célula são relativamente simples reações bioquímicas interligadas, como na glicólise. A diferença está justamente na reação de acoplamento única sobre o nível de conversão de fosfoenolpiruvato (PEP) em piruvato (PYR). Essas vias de fermentação ainda podem culminar na formação de succinato, gerando ATP adicionais, o que caracteriza vantagem bioenergética da fermentação do glicerol. ${ }^{17}$

Durante o catabolismo aeróbico, o glicerol entra na célula microbiana via difusão facilitada ou transporte ativo, em seguida é fosforilada em 3P-gliceraldeído. O último entra na via glicolítica, transformado em ácido pirúvico e, em seguida em acetil-CoA, percursor de uma variedade de produtos metabólicos. ${ }^{18}$ A Figura 2 mostra as vias de fermentação do glicerol e os produtos maioritários formados. 


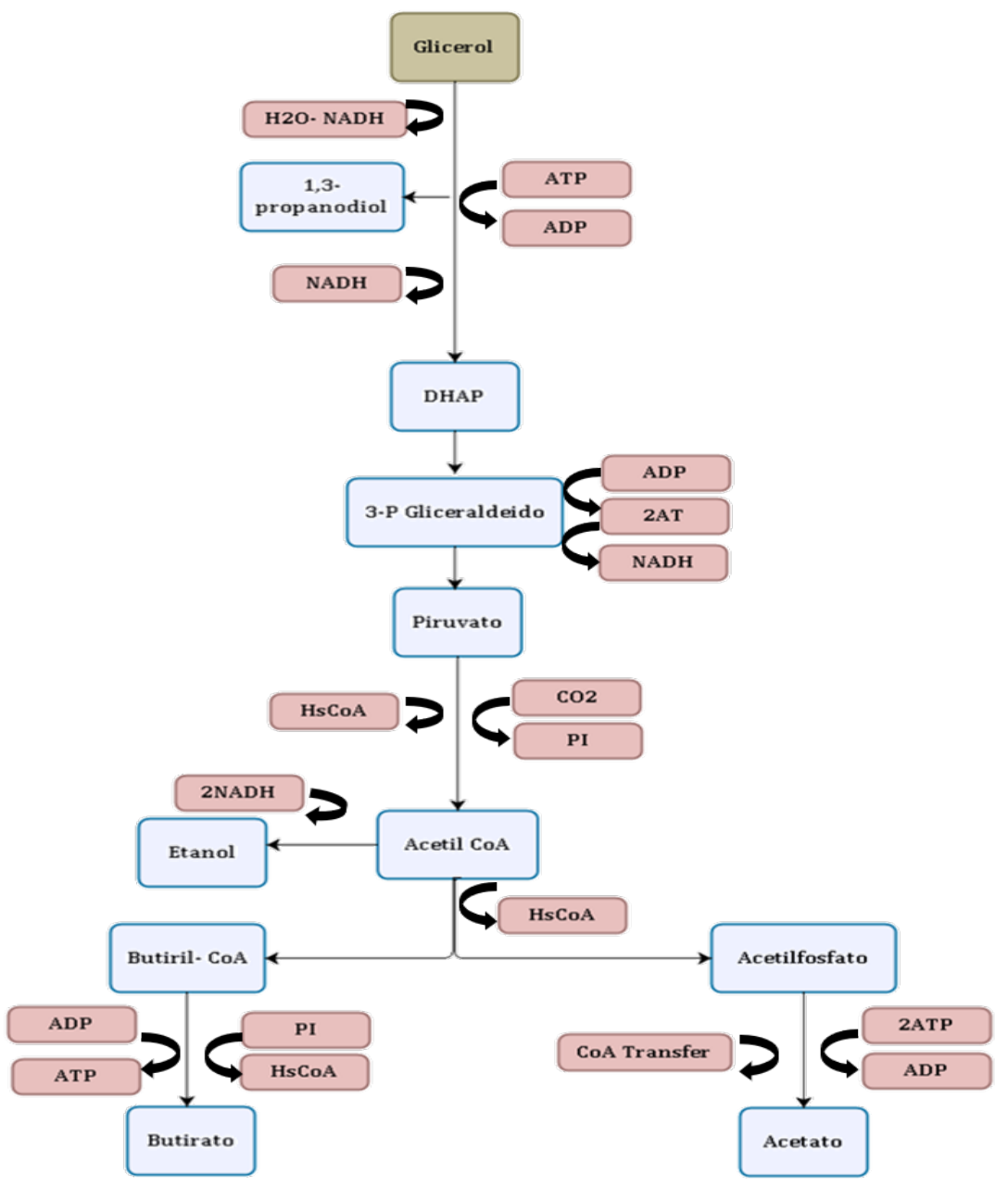

Figura 2 - Via metabólica do glicerol

Fonte: adaptada de Macis, Daniel e Gottschbach. ${ }^{18}$

\section{BIOCONVERSÃO DO GLICEROL PARA PRODUÇÃO DO 1,3-PROPANODIOL}

Como subproduto na fabricação de biodiesel, sabão e ácidos graxos, o glicerol representa ameaça na busca pela sustentabilidade de plantas produtivas, sendo necessária a viabilidade do potencial como componente da matriz energética que possui valor agregado. $\mathrm{O}$ glicerol será potencialmente matéria-prima promissora em biorrefinarias para sintetizar combustíveis, produtos químicos e energia. ${ }^{19}$

Basicamente, o glicerol pode ser transformado em muitos produtos, como hidrogênio, aditivos de combustível, ração animal, componente no tratamento de águas residuárias, entre outros. Essa conversão do glicerol ocorre por processos químicos e biológicos. ${ }^{20,21,22}$ A Figura 3 mostra vasta gama de produtos químicos que podem ser derivados do glicerol. 


\begin{tabular}{|c|c|c|}
\hline Produto & Processos & Aplicação \\
\hline $\begin{array}{l}\text { 1,3-dihidroxiacetoa } \\
\text { (DHA) }\end{array}$ & Oxidação direta e indireta & $\begin{array}{l}\text { Principal ingrediente de cosméticos, } \\
\text { intermediário na síntese de produtos químicos }\end{array}$ \\
\hline 1,2-propanodiol & Hidrogenólise & $\begin{array}{l}\text { Utilizado como plastificante e agente de esta- } \\
\text { bilização }\end{array}$ \\
\hline Ácido fórmico & Oxidação Seletiva & $\begin{array}{l}\text { Portador de energia na célula direta de com- } \\
\text { bustível ácido fórmico }\end{array}$ \\
\hline Ácido succínico & Fermentação com succinogenes Actinobacillus & $\begin{array}{l}\text { Intermediário na produção de produtos quími- } \\
\text { cos na indústria farmacêutica e de alimentos }\end{array}$ \\
\hline Acroleína & $\begin{array}{l}\text { Desidratação a vapor/ Fase gasosa Desidrata- } \\
\text { ção a vapor/ Fase líquida }\end{array}$ & $\begin{array}{l}\text { Intermediário na formação de ácido acrílico e } \\
\text { seus ésteres }\end{array}$ \\
\hline 1,3-propanodiol & $\begin{array}{l}\text { Fermentação usando Klebsiella, Lactoba- } \\
\text { cillus, Cianobacter, etc., Hidrogenólise ou } \\
\text { Hidroformilação }\end{array}$ & $\begin{array}{l}\text { Matéria-prima na produção de lubrificantes, } \\
\text { polímeros, alimentos, solventes, adesivos, re- } \\
\text { moção de fósforo e nitrato de águas residuárias }\end{array}$ \\
\hline 2,3-butanodiol & $\begin{array}{l}\text { Fermentação usando Klebsiella, Lactoba- } \\
\text { cillus, Cianobacter, Clostridium }\end{array}$ & $\begin{array}{l}\text { Borracha sintética, fármaco, cosméticos, aro- } \\
\text { matizantes, combustíveis, corante e produtos } \\
\text { biodegradáveis }\end{array}$ \\
\hline Propanol & Fermentação usando Propanobacterium & $\begin{array}{l}\text { Conservantes de alimentos, precursor de fár- } \\
\text { macos e herbicidas }\end{array}$ \\
\hline Poliésteres & Policondensação & $\begin{array}{l}\text { Usado na indústria têxtil, componente na in- } \\
\text { dústria de tomadas de plástico }\end{array}$ \\
\hline Hidrogênio & $\begin{array}{l}\text { Fermentação usando Escherichia coli, refor- } \\
\text { ma água supercrítica, reforma a vapor, refor- } \\
\text { ma a vapor autotérmica }\end{array}$ & $\begin{array}{l}\text { Síntese de metano e amoníaco, usado em célu- } \\
\text { las de combustível, combustível para motores } \\
\text { de combustão interna }\end{array}$ \\
\hline
\end{tabular}

Figura 3 - Químicos derivados de glicerol

Fonte: adaptada de Atapour e Kariminia, ${ }^{20}$ Pfulgh, Marx, Mattanovich e Sauer ${ }^{21}$ e Kaur, Srivastava e Chand.$^{22}$

As três hidroxilas presentes na estrutura do glicerol promovem a via de conversão biológica com geração de produtos com valor agregado se comparadas ao hidrocarboneto de origem petroquímica em relação ao custo-benefício impraticável. ${ }^{6} \mathrm{~A}$ transesterificação catalisada por enzimas lipases fornece solução para obtenção de produto com menor quantidade de sais inorgânicos, água e catalisadores metálicos e outros. ${ }^{23} \mathrm{O}$ processo é altamente seletivo, envolve menos consumo de energia $\mathrm{e}$ possibilita maior recuperação do glicerol em comparação à catálise alcalina, por exemplo. ${ }^{20}$ Sob esse ponto de vista, produtores de biodiesel conseguem glicerol com purezas entre 95,5 e 99\%, com desafio de comercializá-lo em escala global. ${ }^{24}$ Entretanto, a vulnerabilidade e a sazonalidade do mercado do glicerol acontece mediante a dependência da oferta e da procura global.

\subsection{O 1,3-PROPANODIOL}

O trimetileno glicol ou propileno glicol é um composto alifático, linear, líquido, incolor, inodoro, solúvel em água, álcool e éter, com vasta aplicação na indústria. O 1,3-propanoglicol ou 1,3-propanodiol é a base produtiva dos poliésteres e poliuretanos. Na síntese química desses polímeros são gerados alto custos e subprodutos tóxicos. ${ }^{22} \mathrm{Na}$ Figura 4, tem-se as propriedades físico-químicas do 1,3-PD. 


\begin{tabular}{|l|l|}
\hline \multicolumn{1}{|c|}{ Nome IUPAC } & \multicolumn{1}{c|}{ Propan-1,3-diol } \\
\hline Outros Nomes & 1,3 -propanodiol, trimetilenoglicol, 1,3-di-hidroxi-propano \\
\hline Número do CAS & $504-63-2$ \\
\hline Fórmula molecular & C3H8O2 \\
\hline Solubilidade em água & $100 \mathrm{~g} . \mathrm{L}-1$ \\
\hline Massa molar & $76,09 \mathrm{~g} \cdot \mathrm{mol}-1$ \\
\hline Temperatura de ebulição & $210-212^{\circ} \mathrm{C}$ \\
\hline Temperatura de fusão & $-28^{\circ} \mathrm{C}$ \\
\hline Índice de refração & $1,436\left(20^{\circ} \mathrm{F}\right)$ \\
\hline Densidade & $1,0597 \mathrm{~g} \mathrm{~cm}-3$ \\
\hline Calor específico & $0,53 \mathrm{BTU} / \mathrm{lb} /{ }^{\circ} \mathrm{F}$ \\
\hline Viscosidade & $52 \mathrm{cp}$ \\
\hline Temperatura de fugor & $131^{\circ} \mathrm{C}$ \\
\hline Temperatura de autoignição & $405^{\circ} \mathrm{C}$ \\
\hline Pressão de vapor & $0,08 \mathrm{mmHg}$ \\
\hline
\end{tabular}

Figura 4 - Propriedades físico-químicas do 1,3-propanodiol

Fonte: Kaur, Srivastava e Chand. ${ }^{22}$

O 1,3-propanodiol é um monômero que tem utilidade potencial no fabrico de compostos cíclicos e produção de biopolímeros com propriedades biodegradáveis, como o tereftalato de politrimetileno (PTT). ${ }^{25} \mathrm{O}$ produto é tradicionalmente obtido por via química, a qual ocorre por meio dos derivados do petróleo, como a acroleína e o óxido de etileno, em reações como hidrogenação e hidroformilação, com formação de intermediários tóxicos. ${ }^{26}$ Além da rota química, uma alternativa para a produção do 1,3-propanodiol que vem se destacando é a rota biológica, sendo o principal parâmetro que influencia a cinética na produção de 1,3-propanodiol e a baixa concentração de biomassa, possuindo a literatura descrições de muitas alternativas de meios de cultivo que não tenham o glicerol como única fonte de carbono, aumentando a concentração de biomassa bacteriana. ${ }^{27}$

O 1,3-propanodiol foi um dos primeiros produtos de fermentação microbiana conhecidos. Foi descoberto em 1881 pelo austríaco August Freund em suas investigações em cultura mista contendo Clostridium pasteurianum, e, mesmo sendo conhecido há mais de um século, a impossibilidade de sua produção em larga escala limitou suas inúmeras aplicações. Um estudo verificou que o produto comercial mais útil obtido a partir do glicerol é o 1-3-PDO, tendo a hidrogenólise como ponto de partida. ${ }^{28}$ A Figura 5 mostra as vantagens e desvantagens da conversão de glicerol em 1,3-propanodiol por via química e por via biológica. 


\begin{tabular}{|c|c|c|}
\hline Parâmetros & Conversão Química & Conversão Biotecnológica \\
\hline Matéria-prima & Derivados do petróleo & Glicerol ou Glicerina \\
\hline Temperatura & Altas & Ambiente \\
\hline Pressão & Altas & Usual \\
\hline Subprodutos & Tóxicos & Atóxico \\
\hline Produtividade & Baixa & Alta \\
\hline Rendimento & Alto com catalisador & Relativo \\
\hline Custo operacional & Alto & Baixo \\
\hline
\end{tabular}

Figura 5 - Comparação entre a viabilidade de conversão de glicerol em 1,3-propanodiol

Fonte: Ripoll, Vicente, Morán, Rojas, Segarr, Montesino, et al. ${ }^{26}$

\subsection{A PRODUÇÃO DE 1,3-PROPANODIOL POR VIA BIOTECNOLÓGICA}

Certo número de micro-organismos é capaz de crescer anaerobicamente em glicerol como única fonte de carbono e energia por via redutiva ou oxidativa, como Citrobacter freundii, Klebsiella pneumoniae, Clostridium pasteurianum, Clostridium butyriricum, Enterobacter agglomerans, Enterobacter aerogenes e Lactobacillus reuteri. ${ }^{29}$

Na Klebsiella, Citrobacter, Clostridium e Enterobacter, o glicerol é metabolizado tanto na via oxidativa quanto na via redutiva. A via oxidativa $\mathrm{NAD}^{+}$depende de enzima glicerol desidrogenase (E.C.1.1.1.6), a qual catalisa a conversão de glicerol em di-hidroxiacetona e enzima glicolítica de hidroxiacetona quinase (E.C.2.7.1.2.9); fosforila é o último produto que é canalisado para a glicólise. ${ }^{13} \mathrm{~A}$ via de redução catalisada pela coenzima $\mathrm{B}_{12}$ depende da enzima glicerol dehidratase (E.C.4.2.1.30). A

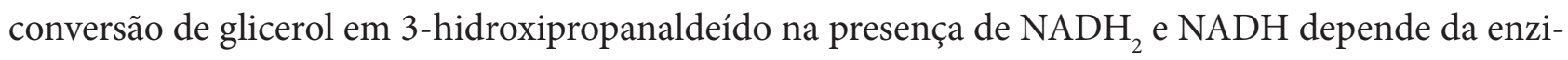
ma 1,3- propanodiol desidrogenase (E.C.1.1.1.202), reduzindo 3-hidroxipropionaldeído em 1,3-propanodiol, regenerando NAD. ${ }^{30}$

\subsection{CONDIÇÕES OPERACIONAIS E VARIÁVEIS ENVOLVIDAS NA PRODUÇÃO DO 1,3-PROPANODIOL}

Abordagens diversas são utilizadas para otimizar a produção microbiana de 1,3-propanodiol, principalmente no que se refere ao tipo de micro-organismo utilizado, tipo de fermentação, temperatura no meio reacional, controle do $\mathrm{pH}$ no início e ao longo do processo. ${ }^{31}$

Embora a literatura indique resultados satisfatórios para a produção de 1,3- propanodiol a partir de glicerol por K. pneumoniae, a utilização dessa bactéria em um processo industrial não é desejável, em razão da sua patogenicidade. ${ }^{25}$ Vários estudos relata ${ }^{\mathrm{m}}$ a possível inibição do processo por baixos valores de $\mathrm{pH}$, em decorrência da síntese de ácidos orgânicos de acordo com a via metabólica, indicando a importância do desenvolvimento de uma estratégia de controle de $\mathrm{pH}$ adequado para melhorar a produção de 1,3-PDO., ${ }^{92,28,22}$ Por meio do controle de $\mathrm{pH}$ apropriado (mantido a um valor de 7,0) e utilizando estirpes de Klebsiella oxytoca (FMCC-197), a partir da mesma quantidade inicial 
do glicerol em bruto, um estudo duplicou a massa final de concentração em volume de 1,3-PDO, com a obtenção de um rendimento 29\% maior e redução do tempo de fermentação de 96 para $32 \mathrm{~h}$. Essa estratégia foi testada com sucesso em experimentos em batelada com outros biocatalisadores, como K. pneumoniae, C. freundii e L. diolivorans. ${ }^{32,21}$

A concentração final de 1,3-propanodiol obtida depende também da natureza e da concentração do substrato, sendo a utilização do glicerol puro geralmente o responsável pelo rendimento e pela produtividade ligeiramente mais baixos. ${ }^{13}$ A presença de glicerol residual no meio leva ao crescimento de biomassa mais elevado, fenômeno que pode ser atribuído à presença de fosfatos e seus sais em glicerol em bruto, resultando em efeito tampão de $\mathrm{pH}$ nas fases iniciais da fermentação. ${ }^{10,20,27}$ O tipo de substrato, evidenciado pela presença de glicerol em residual ou glicerol purificado, é fator na determinação da velocidade de agitação ótima e do efeito de borbulhamento de gás (azoto ou ar) durante a fermentação. ${ }^{34,35}$ Outra estratégia industrialmente importante é a imobilização de células ou enzimas para condução de bioprocessos, já que, teoricamente, os biocatalizadores ficam retidos no meio reacional por mais tempo, aumentando a velocidade de reação e maior produtividade. ${ }^{26}$ Imobilizadores comumente utilizados são o dietil amino etil celulose (DEAE) e o polímero polyhipe ${ }^{\mathrm{TM}}$, uma espuma de vinil poliuretano desenvolvida pela Unilever. ${ }^{26,34}$ A Tabela 1 descreve estratégias de fermentação utilizadas na literatura em termos de rendimento e produtividade do 1,3-PDO.

Tabela 1 - Estratégias de fermentação na produção de 1,3-propanodiol

\begin{tabular}{llrrr}
\hline $\begin{array}{l}\text { Regime de } \\
\text { Processo }\end{array}$ & \multicolumn{1}{c}{ Micro-organismo } & $\mathbf{1 , 3 - P D O}(\mathbf{g} / \mathbf{L})$ & $\begin{array}{c}\text { Rendimento (molDPO/ } \\
\text { mol G) }\end{array}$ & Produtividade g/L/h \\
\hline $\begin{array}{l}\text { Batelada } \\
\text { alimentada }\end{array}$ & C. butyrucum IK124 & 87,0 & 0,68 & 1,9 \\
& C. butyricum AKR 102a & 76,2 & 0,62 & 2,3 \\
& K. pneumoniae ME-303 & 71,5 & 0,65 & 1,93 \\
Contínuo & C. butyricum VPI 3266 & 30 & 0,65 & 10,3 \\
& C. butyricum F2b & $31-48$ & 0,67 & $2,9-5,5$ \\
$\begin{array}{l}\text { Biocataliza- } \\
\text { dores Imo- } \\
\text { bilizados }\end{array}$ & K. pneumoniae & 51,8 & 0,39 & 1,08 \\
& K. pneumoniae & DSM4799 & $48-51$ & 1,16 \\
\hline
\end{tabular}

Fonte: Ripoll, Vicente, Morán, Rojas, Segarr, Montesino, et al. ${ }^{26}$

Em termos industriais e comerciais, a empresa Dupont produz, concomitantemente com a via química, 1,3-propanodiol a partir de estirpes de E. coli em sistema de cofermentação com acréscimo de glicose ao meio reacional em sistemas de batelada alimentada com rendimento de $135 \mathrm{~g} / \mathrm{L}$, e uma produtividade de 3,5 g/L por hora. ${ }^{34}$ Por outro lado, a empresa Sigma-Aldrich disponibiliza a venda de 1,3-propanodiol com 99\% de pureza a partir de 304 dólares a cada 100 gramas de produto, mais as taxas de importação, evidenciando o alto valor agregado ao produto, como se verifica na Tabela 2. 
Tabela 2 - Valor de mercado e produção mundial do 1,3-propanodiol

\begin{tabular}{rrrr}
\hline Ano & $\begin{array}{r}\text { Produção } \\
\text { mundial } \\
\text { (Tonelada) }\end{array}$ & $\begin{array}{r}\text { Valor de mercado esti- } \\
\text { mado pelo autor (U\$\$)/ } \\
\text { Tonelada }\end{array}$ & $\begin{array}{r}\text { Valor de mercado } \\
\text { estimado pelo autor } \\
\text { (U\$\$) }\end{array}$ \\
\hline 2014 & 120,9 & $4.521,16$ & $587.750,77$ \\
2015 & 122,1 & $4.557,92$ & $592.529,23$ \\
2016 & 123,4 & $4.594,67$ & $597.307,69$ \\
2017 & 124,7 & $4.631,43$ & $602.086,15$ \\
2018 & 126,0 & $4.668,19$ & $606.864,62$ \\
2019 & 127,3 & $4.704,95$ & $611.643,08$ \\
2020 & 128,6 & $4.741,70$ & $616.421,54$ \\
2021 & 130,0 & $4.778,46$ & $621.200,00$ \\
\hline
\end{tabular}

Fonte: adaptada de Garg e Jain ${ }^{36}$ e Mariotto. ${ }^{37}$

\section{PRODUÇÃO BIOTECNOLÓGICA DE 2,3-BUTANODIOL A PARTIR DE GLICEROL RESIDUAL}

\subsection{O 2,3-BUTANODIOL}

Como alternativa ao aumento constante da quantidade residual de glicerol oriundo da produção de biodiesel, o subproduto pode ser empregado como fonte de carbono em processos fermentativos industriais, como se abordou anteriormente. Graças a uma composição estrutural rica em lipídeos, os micro-organismos podem empregá-lo como fonte de carbono em substituição a carboidratos, como sacarose, glicose e amido, para a formação de metabólitos por via biológica, como o 2,3-butanodiol. Semelhantes aos demais processos de bioconversão do glicerol residual derivado da produção de biodiesel em produtos de valor agregado, a produção de 2,3-butanodiol é proposta como uma solução para a melhoria da viabilidade econômica das biorrefinarias. ${ }^{26}$

O 2,3-butanodiol, também conhecido como 2,3-BD, 2,3-butileno-glicol, dimetiletileno-glicol ou butano 2,3-diol (nomenclatura IUPAC), apresenta um peso molecular de 90,121 g/mol e fórmula molecular $\mathrm{C}_{4} \mathrm{H}_{10} \mathrm{O}_{2}$. É um composto que apresenta a característica de ser biodegradável, tornando-se favorável ao ambiente. Seu calor de combustão de $27200 \mathrm{~kJ} / \mathrm{kg}$ se compara ao do etanol (29100 kJ/kg) e do metanol $(22100 \mathrm{~kJ} / \mathrm{kg}){ }^{38}$ Além disso, apresenta alto ponto de ebulição $\left(180^{\circ} \mathrm{C}\right)$ e baixo ponto de congelamento $\left(-60^{\circ} \mathrm{C}\right)$, podendo ser utilizado como anticongelante.

O interesse em 2,3-BD começou em 1906, quando Harden e Walpole empregavam Klebsiella pneumoniae para produzir esse composto. ${ }^{13}$ No entanto, as pesquisas e o desenvolvimento de métodos industriais para produção de 2,3-butanodiol iniciaram apenas na década de 1940, durante a Segunda Guerra Mundial, período em que prevaleceu a escassez de matéria-prima para a produção de borracha em razão da crise petrolífera. Esses fatores levaram países como os Estados Unidos e o Canadá a desenvolverem uma planta-piloto, com o objetivo de obter 2,3-butanodiol em 1,3-butadieno, intermediário na produção da borracha sintética. Atualmente, o 2,3-butanodiol é empregado em outros 
processos, sendo, ainda, estudado em razão das suas potencialidades em atuar como alternativa ao petróleo. Gradualmente, prevalece o interesse na avaliação da sua produção por via fermentativa a partir de componentes residuais, como o glicerol oriundo de biorrefinarias, permitindo contribuir para as questões ambientais, minimizando o emprego de fontes não renováveis e possibilitando o desenvolvimento de produtos com valor agregado, como pode ser resumido na Figura $6 .{ }^{26,13}$

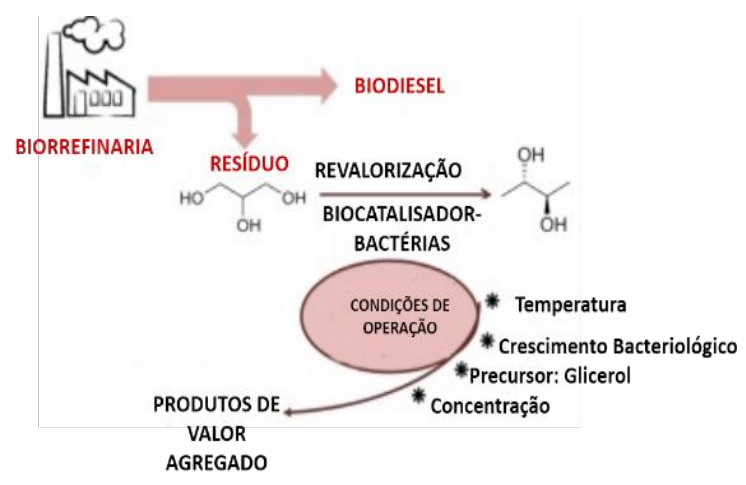

Figura 6 - Etapas envolvidas na biossíntese de 2,3-butanodiol a partir do glicerol residual Fonte: Ripoll, Vicente, Morán, Rojas, Segarr, Montesino, et al. ${ }^{26}$

O 2,3-BD pode existir em três formas isoméricas: D - (-), L - (+) - e meso (Figura 7). Os pontos de ebulição dos três estereoisómeros são ligeiramente diferentes, variando entre 177 e $182^{\circ} \mathrm{C}$, mas, ainda, todos são muito mais elevados do que o ponto de ebulição da água. Embora apresente grande potencialidade industrial, a dificuldade na separação desse produto do meio de cultivo, em decorrência do seu alto ponto de ebulição e da sua afinidade com a água, apresenta-se como um aspecto negativo, o que torna a produção ainda hoje com grande gasto econômico. ${ }^{30,29}$ Assim, métodos alternativos de recuperação de 2,3-BD estão sendo desenvolvidos de maneira a adequar e melhorar a produtividade de uma grande quantidade de produtos químicos por meio desse composto. ${ }^{39}$

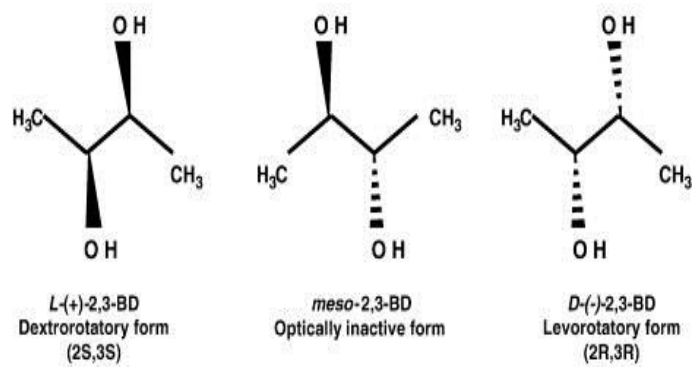

Figura 7 - Formas isoméricas para o 2,3-butanodiol

A produção de 2,3-BD ocorre por meio de processos fermentativos, os quais permitem, a partir do produto majoritário, a produção de diversos outros, como é possível observar a partir da Figura 8, considerando as etapas individuais de desidratação, desidrogenação e cetalização. ${ }^{36}$ 


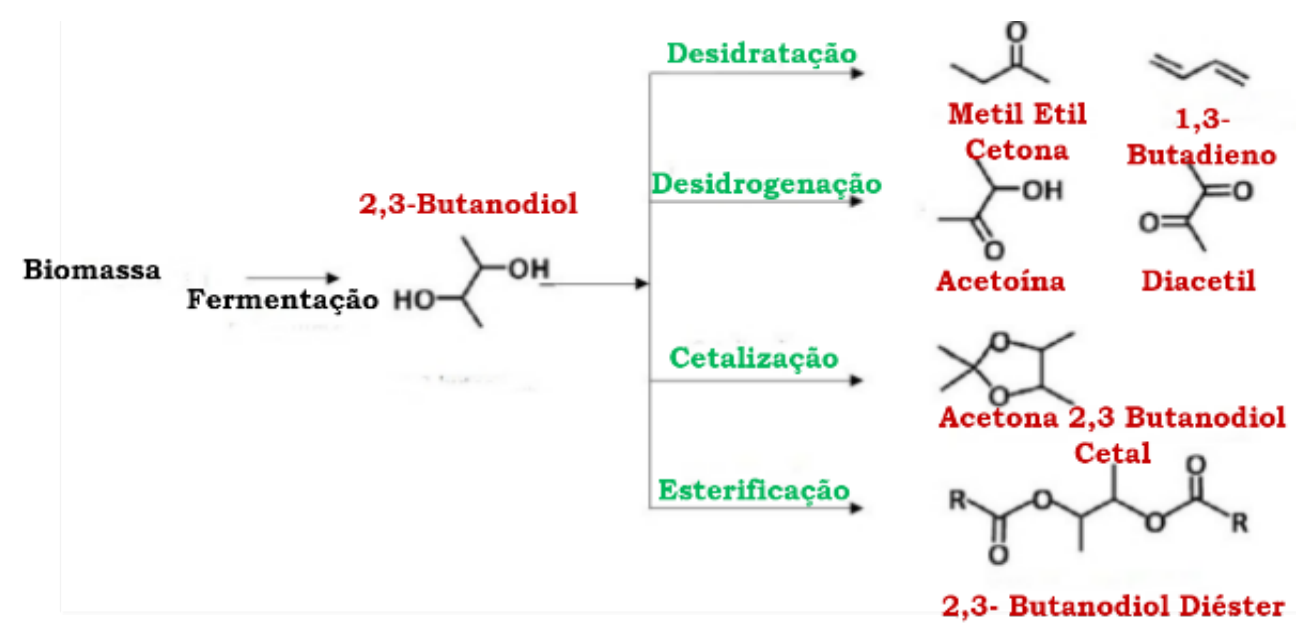

Figura 8 - Derivados de 2,3-butanodiol produzido por via fermentativa

A partir do processo de desidratação, o 2,3-BD permite obter metil-etil-cetona, composto importante como combustível na aviação. Outro produto intermediário dessa etapa é o 1,3-butadieno, obtido geralmente do petróleo e empregado na produção de borracha sintética, eletrodomésticos, calçados, plásticos, modificadores de asfalto, aditivos para óleos lubrificantes, tubos, componentes de construção e látex. ${ }^{36}$

A acetoína produzida por desidrogenação pode ser empregada como aromatizante na indústria alimentícia, assim como o diacetil, intermediário na manutenção do aroma de queijos, manteigas e cremes fermentados. Por meio do processo de cetalização do 2,3-BD, forma-se a acetona 2,3-butanodiol, a qual é misturada na gasolina, sendo uma alternativa ao uso do petróleo em razão do seu alto poder calorífico. Já a partir da esterificação do 2,3-BD, é possível obter constituintes precursores de poliuretano para drogas, loções e cosméticos. Além de apresentar propriedades antissépticas, o 2,3-butanodiol-diéster pode também atuar no desenvolvimento de polímeros termoplásticos, como nitrato de celulose, triacetato de celulose, éster polivinil, polimetilacrilatos, etc. ${ }^{36}$

Além dos produtos mencionados, o elevado calor de combustão $(27.200 \mathrm{~kJ} / \mathrm{kg})$ do 2,3-B se compara favoravelmente ao do etanol $(29.100 \mathrm{~kJ} / \mathrm{kg})$ e ao do metanol $(22.100 \mathrm{~kJ} / \mathrm{kg})$, sugerindo a possibilidade de sua utilização como combustível. O 2,3-butanodiol pode, ainda, ser empregado na manufatura de polímeros, tintas de impressão, perfumes, explosivos, plastificantes e como carriers de produtos farmacêuticos. Acrescenta-se, ainda, o fato de o 2,3-butanodiol ser um composto biodegradável, podendo ser empregado na fabricação de produtos menos agressivos ao meio ambiente. ${ }^{37} \mathrm{Na}$ Tabela 3 é possível observar os valores financeiros para o 2,3-BD no mercado mundial, com estimativas recentes e para um futuro próximo. 
Tabela 3 - Valor de mercado e produção mundial do 2,3-butanodiol

\begin{tabular}{rrrr}
\hline Ano & $\begin{array}{r}\text { Produção mundial (to- } \\
\text { nelada) }\end{array}$ & $\begin{array}{r}\text { Valor de mercado estimado (U\$)/ } \\
\text { tonelada }\end{array}$ & $\begin{array}{r}\text { Valor de mercado estimado } \\
\text { (U\$\$) }\end{array}$ \\
\hline 2010 & 58,3 & $2.200,0$ & $128.260,0$ \\
2011 & 60,0 & $2.270,4$ & $136.335,2$ \\
2012 & 62,0 & $2.343,1$ & $145.200,3$ \\
2013 & 64,0 & $2.418,0$ & $154.641,8$ \\
2014 & 66,0 & $2.495,4$ & $164.997,9$ \\
2015 & 68,1 & $2.575,3$ & $175.406,5$ \\
2016 & 70,3 & $2.657,7$ & $186.812,2$ \\
2017 & 72,5 & $2.742,7$ & $198.959,4$ \\
2018 & 74,9 & $2.830,5$ & $211.896,6$ \\
\hline
\end{tabular}

Fonte: Cision PR Newswire. ${ }^{34}$

\subsection{CONVERSÃO DO GLICEROL EM 2,3-BD POR MICRO-ORGANISMOS}

Os primeiros estudos empregando micro-organismos na obtenção de 2,3-BD datam de 1906. A bactéria utilizada nesses estudos iniciais foi a Klebsiella pneumoniae (anteriormente Aerobacter aerogenes ou Klebsiella aerogenes). Posteriormente, destacou-se o emprego da bactéria Gram-negativa K. oxytoca, a qual apresenta alta capacidade de produção por via bioquímica. Em razão da consolidação desse gênero na produção de 2,3-BD, melhores resultados em escala industrial são relatados na literatura em cultivos de K. oxytoca em regimes descontínuo e descontínuo alimentado, alcançando entre 80 e $90 \%$ de rendimento do produto final. Esse alto rendimento, associado ao rápido crescimento em meios de cultivo simples, tem apontado o gênero K. oxytoca como de grande potencial biotecnológico. ${ }^{26,35,37}$

Além da espécie oxytoca, até o momento K. pneumoniae e P. polymyxa têm sido as mais empregadas na produção eficiente de 2,3-BD. Aerogenes enterobacter e Serratia marcescens também são considerados potenciais micro-organismos, no entanto, as pesquisas com estes são menos relatadas na literatura. Na Tabela 4 é possível observar os rendimentos do produto, alguns substratos e a eficiência de conversão de algumas linhagens de bactérias utilizadas para a produção de 2,3-BD.

Tabela 4 - Produção de 2,3-butanodiol usando diferentes espécies de bactérias

\begin{tabular}{ccrr}
\hline Micro-organismo & Substrato & $\mathbf{2 , 3}$ BD (g.L-1) & Referência \\
\hline Klebsiella pneumoniae & Glicose & 94,2 & 38 \\
Klebsiella pneumoniae & Sabugo de milho & 78,9 & 39 \\
Klebsiella pneumoniae & Glicerol & 49,2 & 40 \\
Klebsiella oxytoca & Glucose & 130,0 & 17 \\
Serratia marcescens & Sacarose & 152,0 & 41 \\
Paemibacillus polymyxa & Alcachofra de Jerusalém & 36,9 & 42 \\
\hline
\end{tabular}

Uma vasta gama de monossacarídeos pentose ou hexoses pode ser fermentadas para produzir 2,3-BD, como detalhado na Tabela 4. No metabolismo bacteriano, monossacarídeos devem inicialmente ser convertidos em piruvato antes da formação de produtos principais. A partir de glucose, o 
piruvato é formado de uma maneira relativamente simples, por meio da via de Embden Meyerhof (glicose). Durante o processo fermentativo, a bactéria, independentemente do substrato, excreta 2,3-BD, etanol, ácido acético, ácido fórmico, acetoína, ácido láctico e ácido succínico, além de gás carbônico e hidrogênio (Figura 9). 27,40,39

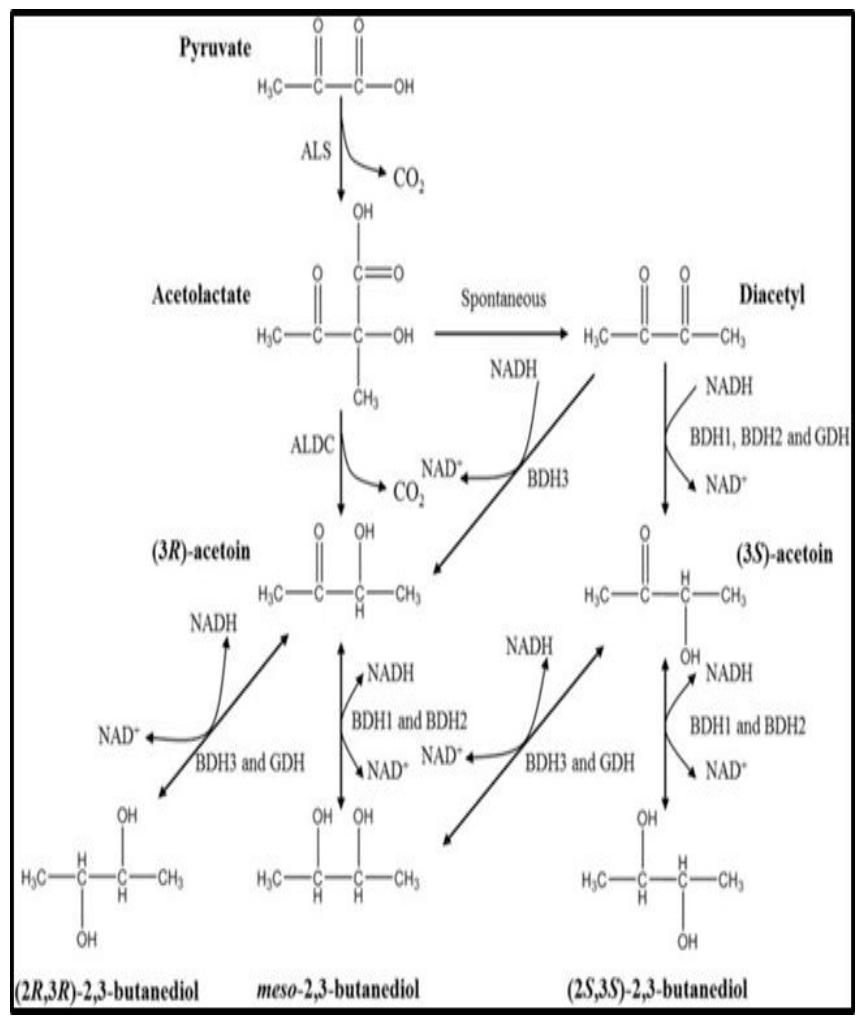

Figura 9 - Via metabólica de 2,3-BD a partir de glicerol

Finalizando o processo fermentativo, o meio contém múltiplas substâncias que devem ser separadas do produto de interesse. De maneira geral, tais substâncias se encontram diluídas em água, em um meio contendo nutrientes residuais, sais e outros produtos da fermentação. Essas impurezas devem ser separadas, sendo esta etapa uma das mais onerosas do processo. ${ }^{39}$ Estritamente para produção do 2,3-BD, em razão do seu alto ponto de ebulição e da sua afinidade com a água, a separação do meio de cultura tem sido um desafio nos últimos tempos. Atualmente são empregadas técnicas de destilação e osmose reversa, no entanto, são necessárias elevadas concentrações do produto de interesse a fim de compensar os altos custos da etapa de recuperação. ${ }^{27,40} \mathrm{O}$ processo completo de obtenção do 2,3-BD a partir do glicerol pode ser resumido conforme processo descrito na Figura 10. 


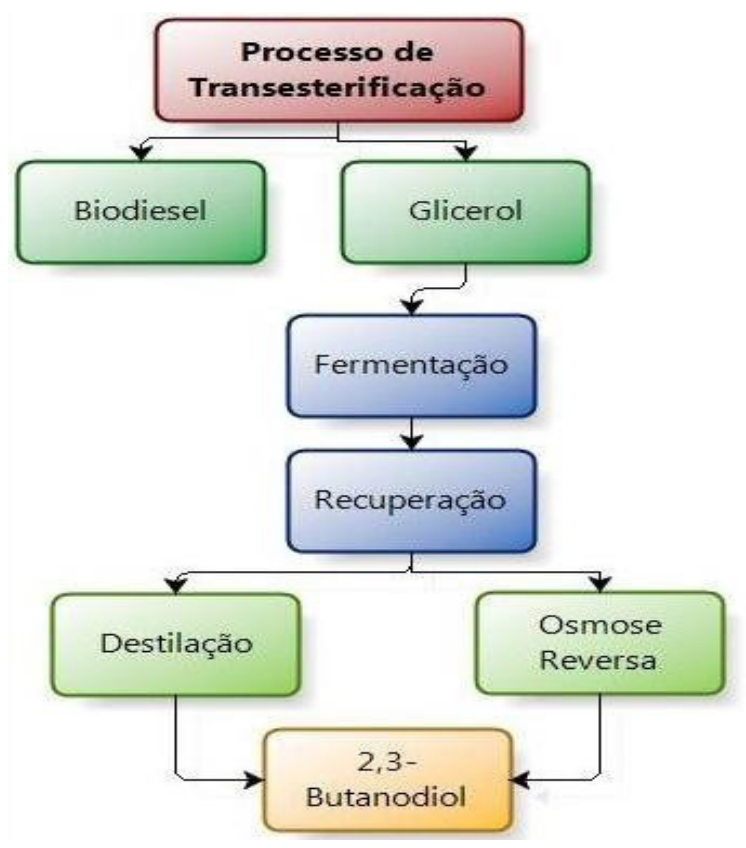

Figura 10 - Esquema representacional para a produção biotecnológica do 2,3-butanodiol a partir do glicerol residual

\subsection{CONDIÇÕES OPERACIONAIS E VARIÁVEIS ENVOLVIDAS NA PRODUÇÃO BIO- TECNOLÓGICA DO 2,3-BUTANODIOL}

Recentemente, o 2,3 butanodiol obtido a partir do glicerol tem recebido atenção em decorrência de sua ampla aplicabilidade. ${ }^{27,29,26}$ Dessa forma, diversos micro-organismos são citados na literatura como metabolizadores do glicerol em 2,3-butanodiol, destacando-se os gêneros Klebsiella, Bacillus, Aeromonas, Enterobacter, Escherichia e Serratia. ${ }^{32,27,40,13,38}$ Entre as diversas espécies bacteriológicas empregadas, o gênero Klebsiella oxytoca é o mais citado na literatura, apresentando um sistema metabólico de conversão bem estruturado e consolidado. No entanto, estudos recentes publicados demonstraram o emprego de outras espécies, como pode ser visualizado na Tabela 5.

\subsubsection{Substrato e concentração}

Em estudo ${ }^{13}$ que trabalhou na produção de 2,3-BD a partir do glicerol em regime descontínuo e descontínuo alimentado em biorreator de bancada, avaliaram-se diversas condições de cultivo para a espécie Klebsiella oxytoca. Entre os principais resultados abordados no estudo, inicialmente observou-se durante o cultivo de Klebsiella oxytoca em meio contendo glicerol e glicose que a velocidade média de formação de biomassa e a máxima velocidade de crescimento celular foram semelhantes entre ambos os substratos, $0,38 \mathrm{~g} / \mathrm{L} / \mathrm{h}$ e $0,63 \mathrm{~h}^{-1}$ para o primeiro constituinte e $0,44 \mathrm{~g} / \mathrm{L} / \mathrm{h}$ e $0,69 \mathrm{~h}-1$ para o glicerol. Para o blend glicerol/glicose se observou uma maior velocidade de consumo para a glicose. Quando os dois substratos estão disponíveis para o micro-organismo, a glicose é preferencialmente selecionada, por se tratar de um composto formado por carboidratos simples e de fácil oxidação. 
Tabela 5 - Produção biotecnológica de 2,3-butanodiol a partir do glicerol residual empregando diferentes espécies de bactérias

Espécie

Literatura

\begin{tabular}{lr}
\hline Klebsiella oxytoca & 16,32 \\
Klebsiella oxytoca (M1) & 48 \\
Klebsiella oxytoca modificada (M2) & 47 \\
Raoultella planticola e Raoultella terrigena & 49 \\
Enterobacter aerogenes & 50 \\
Bacillus amyloliquefaciens & \\
\hline
\end{tabular}

Quando apenas o glicerol está presente, o micro-organismo possivelmente se adapta e oxida o substrato com velocidade superior. Sua composição química de três carbonos permite a oxidação na via bioquímica e formação de um mol de piruvato por mol de glicerol, ao contrário da glicose, para a qual um mol de glicose forma dois mols de piruvato. Dessa forma, a partir de dois mols de glicerol, forma-se um mol de 2-3BD, com fator máximo de conversão de 0,489 g do produto/g de glicerol, enquanto para a glicose, a relação é de $0,500 \mathrm{~g} / \mathrm{g}$. Esses dados demonstram o glicerol mais redutor que a glicose, gerando maior quantidade de $\mathrm{NADH}^{+} \mathrm{H}^{+}$na sua oxidação. ${ }^{13}$

A avaliação do efeito da concentração inicial de glicerol é outro ponto que chama a atenção. Sobre o processo em regime descontínuo, os resultados observados na literatura para as diferentes concentrações de substrato apontam que concentrações superiores a $100 \mathrm{~g} / \mathrm{L}$ podem inibir o desenvolvimento da biomassa na fase exponencial. Uma pesquisa ${ }^{13}$ demonstrou que se obtiveram os melhores resultados em termos de formação de produtos em ensaios empregando glicerol na concentração de $100 \mathrm{~g} / \mathrm{L}$ (17,7 g/L de 2,3-butanodiol e 2,5 g/L de etanol), com rendimentos em relação ao máximo teórico de 57,2 e 7,6\%, respectivamente; abaixo de $40 \mathrm{~g} / \mathrm{L}$ não houve formação do produto. Com as concentrações iniciais do substrato superiores (acima de $100 \mathrm{~g} / \mathrm{L}$ ), a velocidade máxima de crescimento foi reduzida significativamente, indicando inibição por substrato. Avaliando o efeito inibitório do glicerol e de alguns produtos de fermentação formados por K. pneumoniae em uma faixa de $\mathrm{pH}$ entre 5,3 e 8,5, o estudo demonstrou concentrações críticas de algumas substâncias tóxicas para a célula, como: 0,35 g/L de acetato, 16,6 g/L de etanol, 71,4 g/L de 1,3-propanodiol e 187,6 g/L de glicerol. No entanto, em um outro trabalho ${ }^{13}$ verificou-se que a partir de $160 \mathrm{~g} / \mathrm{L}$ houve uma inviabilização no crescimento celular, ou seja, valores mais baixos ao modelo matemático do estudo citado anteriormente.

Trabalho $^{13}$ semelhante foi desenvolvido na China. Comparado o emprego do glicerol residual e do glicerol puro, no estudo encontraram-se rendimentos consideráveis empregando o gênero Klebsiella oxytoca (M1) e a espécie modificada geneticamente Klebsiella oxytoca M3. Na fermentação em regime contínuo, alimentada com a estirpe $K$. oxytoca M1, o glicerol bruto foi mais eficaz do que o glicerol puro como uma fonte de carbono na produção de 2,3-BDO (59,4x 73,8 g/L) e coproduto de redução (1,3-PDO 8,9 vs. 3,7 g.L-1ㄹ ácido láctico, 18,6 x 9,8 g. L-1). Quando se empregou a espécie modificada geneticamente, a produtividade, o crescimento celular e o consumo de glicerol foram significativamente aumentados em ambos os substratos, sendo a produção de 2,3-BDO 1,9 vezes maior do que a da espécie não modificada geneticamente $\left(59,4\right.$ x 115,0 g.L $\left.\mathrm{L}^{-1}\right)$ com 6,9 g.L $\mathrm{L}^{-1}$ de 1,3-propanodiol 
(1,3PDO) e uma pequena quantidade de ácido láctico $\left(0,7 \mathrm{~g} . \mathrm{L}^{-1}\right)$, adotando o glicerol puro como substrato. Notoriamente, quando se empregou glicerol bruto, a partir da espécie modificada, obteve-se -2,3-livre com elevada concentração $\left(131,5 \mathrm{~g} \cdot \mathrm{L}^{-1}\right)$, produtividade de $0,84 \mathrm{~g} \cdot \mathrm{L}^{-1} \mathrm{~h}^{-1}$. Entre os resultados observados na literatura, esta foi a maior produção de 2,3-BDO a partir de fermentação do glicerol verificada.

$\mathrm{O}$ estudo ${ }^{37}$ em que se empregou glicose como fonte de carbono para degradação microbiana teve como objetivo verificar a influência da fonte de nitrogênio, $\mathrm{pH}$ e transferência de oxigênio no crescimento da bactéria Bacillus polymyxa para a formação dos aromas acetoína e 2,3-butanodiol. Semelhantemente aos resultados observados pelos estudos mencionados anteriormente, utilizando a glicose como substrato verificou-se que o controle de $\mathrm{pH}$ tende a favorecer o crescimento do micro-organismo e o consumo da glicose. O ensaio realizado em biorreator também demonstrou que a aeração contínua tende a prejudicar a formação dos produtos, e que o oxigênio favorece o crescimento do micro-organismo apenas no início do cultivo. ${ }^{37}$

\subsubsection{Avaliação do pH de trabalho}

Em relação ao $\mathrm{pH}$ de trabalho, dados da literatura têm apontado que à medida que o meio se torna mais ácido ocorre limitação do crescimento celular. Em experimentos empregando $\mathrm{CaCO}_{3}$ como agente tamponante, observou-se comportamento diferente em razão da neutralização de compostos ácidos presentes no meio pelo carbonato de cálcio. ${ }^{13} \mathrm{~A}$ velocidade de conversão do glicerol também é afetada quando se realiza o controle do $\mathrm{pH}$. No meio em que não ocorre o controle, o consumo do substrato tende a ocorrer mais lentamente, constatando-se uma concentração residual de glicerol de 2,6 g/L após 24 horas de processo, ao passo que, no ensaio em que se realizou o controle de $\mathrm{pH}$, o substrato foi totalmente consumido em 15 horas. ${ }^{13}$ Os melhores resultados observados no meio com $\mathrm{pH}$ tamponado podem ocorrer em virtude de um $\mathrm{pH}$ inadequado modificar o potencial redox da célula, inativar as enzimas de oxidação e alterar as vias metabólicas de formação de produtos. Esses fatores tendem a limitar o crescimento microbiano e, consequentemente, levar à pouca formação de compostos oxidados que serão empregados na formação de produtos de interesse. ${ }^{40}$

\subsubsection{Efeito do suprimento de oxigênio}

O efeito do suprimento de oxigênio é outro fator que tende a afetar o processo de fermentação do glicerol. Dados da literatura tem apontado maior crescimento de micro-organismos quando a concentração de oxigênio disponível no meio se encontra acima da concentração crítica, ou seja, nas primeiras horas de cultivo. De maneira geral, o fator limitante nos testes referentes ao suprimento de oxigênio tem sido o tempo de processo. Ensaios realizados com concentração mais alta apresentaram duração do cultivo mais longa, em decorrência do menor crescimento celular, prejudicando a produtividade. Esses dados permitiram inferir que, em regime descontínuo, concentrações intermediárias do substrato em um menor tempo são mais favoráveis ao aumento da produtividade, observação 
também constatada em outros estudos. ${ }^{13}$ Sob esse aspecto, é possível que quando baixas concentrações de oxigênio se encontram no meio de cultivo o processo de respiração celular seja influenciado, possibilitando uma maior produção de 2,3-butanodiol. ${ }^{13}$

Relacionado ao teor de oxigênio, um estudo empregando glicose como fonte de carbono para degradação microbiana da glicose para formação dos aromas acetoína e 2,3-butanodiol relata que, a partir de um determinado período do processo, o oxigênio passa a ser indesejado, pois a formação dos produtos ocorre por processo fermentativo, e a presença deste afeta consideravelmente a concentração final dos produtos de interesse. Embora a glicose seja um carboidrato simples e de fácil oxidação, os resultados obtidos mostraram-se bem abaixo dos resultados do rendimento para o 2,3-BD observados em outra investigação. ${ }^{13}$ Embora neste último estudo não se tenha considerado individualmente o teor de acetoína e 2,3-BD, os valores encontrados apresentaram-se aproximadamente $53 \mathrm{~g} / \mathrm{L}$ a mais de concentração de ambos os produtos. Essas observações permitem afirmar que o glicerol pode ser empregado de forma eficiente como substrato em substituição à glicose, permitindo a geração de compostos de interesse em ampla escala. ${ }^{13,37}$

\subsubsection{Regime de trabalho}

Tratando-se do regime de trabalho, na avaliação do processo em regime descontínuo alimentado, um estudo ${ }^{13}$ chamou a atenção para a viabilização da produção de 2,3-BD em escala industrial, sendo necessária a obtenção de elevadas concentrações de produto no processo fermentativo. Nesse processo, a obtenção de uma quantidade significativa de produto tem relação com a massa de substrato empregada. Em regime descontínuo, demonstra-se que os melhores resultados em termos de formação de 2,3-BD foram verificados com glicerol inicial de 129 g.L $\mathrm{L}^{-1}$, obtendo-se 53,6 g.L $\mathrm{L}^{-1}$ do produto, concentração considerada insatisfatória. Comparados os dois métodos de operação, foi possível constatar um aumento de 40\% na concentração final do 2,3-BD no regime descontínuo alimentado para ensaios que apresentaram um rendimento em 2,3 BD próximos. Com a condução do processo em regime descontínuo alimentado, como alternativa para contornar os efeitos de inibição pelo substrato, resultados expressivos foram alcançados com a massa de glicerol equivalente à que seria necessária para se ter 202 g. $\mathrm{L}^{-1}$ em regime descontínuo. Nessas condições, 92,1 g.L $\mathrm{L}^{-1}$ de 2,3-butanodiol e rendimento de $92,6 \%$ foram alcançados em 84 horas de fermentação. Os resultados revelam o grande potencial de uso de glicerol como substrato para a produção de 2,3-butanodiol em escala industrial. Quanto ao etanol, os rendimentos do produto foram menores nos ensaios em regime descontínuo alimentado, com baixas produtividades para todos os ensaios.

Ao se avaliar a obtenção de 2,3-BD a partir do glicerol e se empregar regime de trabalho contínuo, verificou-se inicialmente a concentração do substrato (glicerol residual de glicerol puro) em 30, 60 e 90 g.L $\mathrm{L}^{-1}$ em biorreator de 2L, empregando bactérias do gênero Raoultella planticola e Raoultella terrígena. ${ }^{26}$ Analisando os dois substratos individualmente, verificou-se uma queda brusca do $\mathrm{pH}$ nas primeiras 15 horas de ensaio, alcançando valores entre 5,0 e 5,5. Essa redução é menos drástica 
quando o glicerol bruto é utilizado em decorrência do efeito tamponante dos teores de sais e fosfatos presentes no glicerol residual, efeito semelhante ao relatado em estudo ${ }^{13}$ anteriormente citado.

Entre os principais dados da literatura consultados, o consumo total de glicerol é conseguido em todas as experiências com valores diferentes de tempo, dependendo do micro-organismo. Em um estudo $^{26}$ observou-se que a bactéria $R$. planticola requer entre 50 e 65 horas, enquanto $R$. terrigena requer entre 30 e 45 horas, o que ocasiona impactos sobre os valores de produtividade. Trabalhando com concentração máxima de glicerol no teor de $90 \mathrm{~g}$. $\mathrm{L}^{-1}$, verificou-se maior rendimento para a espécie $R$. planticola. No entanto, R. terrigena apresentou maior produtividade de 2,3-BD. Quando R. planticola é empregada como biocatalisadora, a concentração máxima de 2,3-BD, o rendimento e a produtividade foram de $30,5 \mathrm{~g} . \mathrm{L}^{-1}, 0,38 \mathrm{~g} / \mathrm{g}$ e $0.30 \mathrm{~g} \cdot \mathrm{L}^{-1} \cdot \mathrm{h}^{-1}$, respectivamente. Por outro lado, quando se emprega a espécie $R$. terrigena, os mesmos teores são respectivamente de $27,3 \mathrm{~g} \cdot \mathrm{L}^{-1}, 0,32 \mathrm{~g} / \mathrm{g}$ e $0.37 \mathrm{~g} \cdot \mathrm{L}^{-1} \cdot \mathrm{h}^{-1}$.

A conversão eficiente do glicerol residual em 2,3-BD foi relatada de maneira categórica na literatura consultada, no entanto, apenas um dos trabalhos mencionou a produtividade em escala industrial, a qual deve ser realizada em sistema com regime de trabalho descontínuo alimentado. Três estudos obtiveram melhores resultados de produtividade trabalhando com glicerol residual, ao passo que, embora o glicerol puro seja mais rapidamente convertido, sua produtividade se mostrou mais baixa. É visto que a produção industrial do produto analisado depende de diversos fatores, como a concentração do glicerol (principal), o pH de trabalho e o sistema de aeração, variáveis consideradas nos trabalhos analisados. Na Tabela 6 são representados os principais resultados obtidos na literatura para conversão do glicerol em 2,3-butanodiol a partir de diferentes regimes de trabalho.

Tabela 6 - Condições verificadas na literatura para mesma produção de 2,3-butanodiol a partir do glicerol residual em diferentes regimes de trabalho

\begin{tabular}{rlrr}
\hline Autor & Regime de trabalho & Rendimento & Produtividade Vol. (g.L-1.h-1) \\
\hline \multirow{2}{*}{16,32} & Descontínuo & $53,6 \mathrm{~g} / \mathrm{L}$ & 1,10 \\
& & $83,7 \%$ & \\
& Descontínuo alimentado & $92,1 \mathrm{~g} / \mathrm{L}$ & 1,09 \\
\multirow{2}{*}{48} & & $92,6 \%$ & 0,39 \\
& & $73,8 \mathrm{~g} / \mathrm{L}$ & 0,84 \\
& & $131,5 \mathrm{~g} / \mathrm{L}$ & 0.23 \\
\multirow{2}{*}{30} & Concontínuo alimentado & $27.5 \mathrm{~g} / \mathrm{L}$ & 0.35 \\
& & $50.0 \%$ & \\
\multirow{2}{*}{49} & & $33.6 \mathrm{~g} / \mathrm{L}$ & 0.42 \\
\multirow{2}{*}{50} & Contínuo & $61.3 \%$ & 0.71 \\
\hline
\end{tabular}

\section{CONSIDERAÇÕES FINAIS}

Um fator importante para o aprimoramento e consolidação dos processos de fermentação bem-sucedidos para a produção de diois é a disponibilidade de um substrato de baixo custo. Nesse as- 
pecto, o glicerol residual proveniente da síntese do biodiesel é considerado uma matéria-prima renovável, econômica e abundante para os processos microbiológicos. Nas últimas décadas e nos próximos anos, grandes quantidades desse material deverão ser produzidas, gerando quantidades excedentes de materiais residuais. Uma alternativa para a diminuição desse excedente pode ocorrer por meio da bioconversão desse resíduo em produtos de valor agregado, como 1,3-propanodiol e o 2,3-butanodiol.

O 1,3-propanodiol e o 2,3-butanodiol, por serem processados por via química ou biotecnológica, tornaram-se alvo de diversos estudos das áreas de química e biotecnologia, as quais estão em desenvolvimento com a finalidade de atender ao mercado consumidor. Entre as vias pesquisadas, a fermentação do glicerol vem sendo a mais promissora. A utilização dessa metodologia é favorável para o mercado, pois se trata de uma categoria renovável, com baixo custo, sendo que a matéria-prima comum para a obtenção desses produtos atualmente são os combustíveis fósseis. A conversão biotecnológica otimiza o processo, pois elimina os custos operacionais químicos que envolvem o uso de altas temperaturas e altas pressões, além de resíduos tóxicos, que não favorecem o uso do glicerol com pureza não elevada.

As biorrefinarias objetivam a substituição de processos únicos por uma maior diversificação à base de petróleo, quando possível, tudo isso por meio do uso de micro-organismos modificados, os quais são metabolicamente apropriados à produção de químicos úteis em escala industrial e de combustíveis a partir de biomassa renovável, evitando-se, assim, a maneira dependente dos recursos fósseis que vêm se aplicando de forma demasiada. Como parte dessa premissa, a conversão biológica de resíduos de glicerol derivados de biodiesel em uma variedade de produtos de valor agregado requer, além de substrato de baixo custo, um bioprocesso economicamente viável e competitivo. Atualmente, o principal empasse que restringe a produção biológica dos produtos analisados é o alto custo do processamento, principalmente a etapa de purificação. Alternativas como o uso de eletrodiálise vêm sendo debatidas na literatura, no entanto, a rápida contaminação das membranas dificulta o processo. Além disso, os pontos de ebulição e as características hidrofílicas dos materiais tornam o processo de recuperação ainda mais complexo.

Agregando os conceitos de biorrefinarias e as problemáticas que dificultam a conversão biológica do glicerol residual, são interessantes e promissoras pesquisas com ênfase na melhoria dos processos biotecnológicos, uma vez que a bioconversão de resíduos de glicerol derivados de biodiesel em produtos de alto valor é proposta como uma solução para melhorar a viabilidade econômica das biorrefinarias. Dessa forma, novos estudos são necessários para apontar estratégias eficientes para o desenvolvimento de produtos químicos intermediários e industriais, agregando, simultaneamente, condições reacionais leves, segurança ambiental e produtos de ampla disponibilidade, além do menor consumo e custo de energia. 


\section{REFERÊNCIAS}

1. Metsoviti M, Paraskevaidi K, Koutinas A, Zeng AP, Papanikolaou S. Production of 1,3-propanediol, 2,3-butanediol and ethanol by a newly isolated Klebsiella oxytoca strain growing on biodiesel-derived glycerol based media. Process Biochem. 2012;47:1872-82. doi:10.1016/j.procbio.2012.06.011.

2. Saxena RK, Anand P, Saran S, Isar J. Microbial production of 1,3-propanediol: Recent developments and emerging opportunities. Biotechnol. Adv. 2009;27:895-913. doi: 10.1016/j.biotechadv.2009.07.003.

3. Yazdani SS, Gonzalez R. Anaerobic fermentation of glycerol: a path to economic viability for the biofuels industry. Curr. Opin. Biotechnol. 2007;18:213-9. doi: 10.1016/j.copbio.2007.05.002.

4. Cui C, Zhang Z, Chen B. Environmentally-friendly strategy for separation of 1,3-propanediol using biocatalytic conversion. Bioresour. Technol. 2017; 245:477-82. doi: 10.1016/j.biortech.2017.08.205.

5. Wonga CL, Huang CC, Luc WB, Chen WW, Chang JS. Producing 2,3-butanediol from agricultural waste using an indigenous Klebsiella sp. Zmd30 strain. Biochem. Eng. J. 2012;69:32-40.

6. Knothe G, van Gerpen J, Krahl J, Ramos LP. Manual de biodiesel. São Paulo: Blucher, 2006; 352 p.

7. Balat M, Balat H. Progress in biodiesel processing. Appl. Energy. 2007;87:1815-35. doi. org/10.1016/j.psep.2007.12.005.

8. Goembira F, Matsuura K, Saka S. Biodiesel production from rapeseed oil by various supercritical carboxylate esters. Fuel. 2012;97:373-8. doi.org/10.1016/j.fuel.2012.02.051

9. Johnson EE, Rehmann L. The role of 1,3-propanediol production in fermentation of glycerol by Clostridium pasteurianum. Bioresour Technol. 2016;209:1-7. doi: 10.1016/j.biortech.2016.02.088.

10. Shahid EM, Jamal Y. Production of biodiesel: A technical review. Renewable \& Sustainable Energy Reviews. 2011;15(9):4732-45. doi:10.1016/j.rser.2011.07.079.

11. Lane J. Biofuels mandates around the world. Biofuels Digest. 2014.

12. Kuhn J, Müller H, Salzig D, Czermak P. A rapid method for an offline glycerol determination during microbial fermentation. Electron. J. Biotechnol. 2015;18(3):252-5. doi: 10.1021/ic0604967.

13. Romio T, Hartmann C, Viapiana F, Meneghel L, Carra S, Torre AP, et al. Cultivo de Klebsiella oxytoca em glicerol para produção de 2,3-butanodiol em biorreator de bancada. In: Anais do XX Congresso Brasileiro de Engenharia Química, 2014; Florianópolis. p. 1-7.

14. Anitha M, Kamarudin SK, Kofli, NT. The potential of glycerol as a value-added commodity. Chem. Eng. J. 2016;295:119-30. doi: 10.1016/j.cej.2016.03.012. 
15. Vikromvarasiri N, Haosagul S, Boonyawanich S, Pisulpaisal, N. Microbial dynamics in ethanol fermentation from glycerol. Int J Hydrogen Energy. 2016;41:15667-73. doi: 10.1016/j.ijhydene.2016.04.188.

16. Soo CS, Yap W, Hon W, Raml N, Shah UKM, Phang L. Co-production of hydrogen and ethanol by Escherichia coli SS1 and its recombinant. Eletron J Biotechnol. 2017;30:64-70. doi: 10.1186/ s13068-016-0510-5.

17. Chatzifragkou A, Papanikolaou S. Effect of impurities in biodiesel-derived waste glycerol on the performance and feasibility of biotechnological processes. Appl Microbiol Biotechnol. 2012;95(1):13-27. doi:10.1007/s00253-012-4111-3.

18. Macis L, Daniel R, Gottschbach G. Properties and sequence of the coenzime B-12 dependent glycerol dehidratase of Clostridium Pasteurianum. FEMS Microbiology. 1998;164:21-8.

19. Brander A, Lehnert K, Bienholz A. Lucas M, Claus P. Production of Biomass Derived Chemicals and Energy: Chemocatalytic Conversions of Glycerol. Topic in Catalysis. 2009;52(3):278-87.

20. Atapour M, Kariminia HR. Characterization and transesterification of Iranian bitter almond oil for biodiesel production. Appl. Energy. 2011;88(7):2377-81. doi:10.1016/j.psep.2011.12.005.

21. Pfulgl M, Marx S, Mattanovich H, Sauer D. 1,3 Propanediol production from glycerol with Lactobacillus diolivorans. Bioresource Thecnology. 2012;119:133-40. doi: 10.1016/j.biortech.2012.05.121.

22. Kaur G, Srivastava AK, Chand S. Advances in biotechnological production of 1,3 propanediol. Biochem. Eng. J. 2013;64:106-18. doi: 10.1016/j.bej.2012.03.002.

23. Haas MJ, Mcaloon AJ, Yee WC, Foglia TA. A process model to estimate biodiesel production costs. Bioresour. Technol. 2006;97(4):671-8. doi:10.1016/j.biortech.2005.03.039.

24. Haas MJ, Mcaloon AJ, Yee WC, Foglia TA. A process model to estimate biodiesel production costs. Bioresour. Technol. 2006;97(4):671-8. doi:10.1016/j.biortech.2005.03.039.

25. Hermann BG, Patel M. Today's and tomorrow's bio-based bulk chemicals from white biotechnology: a techno-economic analysis. Appl. Biochem. Biotechnol. 2007;136(3):1-6.

26. Ripoll V, Vicente G, Morán B, Rojas A, Segarr S, Montesino A, et al. Novel biocatalysts for glycerol conversion into 2,3-butanediol. Process Biochem. 2016;51(6):740-8. doi: 10.1016/j.procbio.2016.03.006.

27. Ji XJ, Huang H, Ouyang PK. Microbial 2,3-butanediol production: a state-of-the-art review. Biotechnol. Adv. 2011;29(3):351-64. doi: 10.1016/j.biotechadv.2011.01.007

28. Edake M, Dalil M, Mahboub MJD, Dubois JL, Patience GS. Catalytical glycerol hydrogenolysis to 1,3 propanediol. RSV Adv. 2017;7:3853-60. doi: 10.1039/C6RA27248G 
29. Celińska E, Grajek W. Biotechnological production of 2,3-butanediol-current state and prospects. Biotechnol. Adv. 2009;27(6):715-25. doi: 10.1016/j.biotechadv.2009.05.002.

30. Zhang L, Yang Y, Sun J, Shen Y, Wei D, Zhu J, et al. Microbial production of 2,3-butanediol by a mutagenized strain of Serratia marcescens H30. Bioresour. Technol. 2010;101(6):1961-7. doi: 10.1016/j.biortech.2009.10.052.

31. Perego P, Converti A, Del Borghi M. Effects of temperature, inoculum size and starch hydrolyzate concentration on butanediol production by Bacillus licheniformis, Bioresour. Technol. 2003;89(2):125-31.

32. Szymanowska-Powałowska D. 1,3-Propanediol production from crude glycerol by Clostridium butyricum DSP1 in repeated batch. Electron. J. Biotechnol. 2014; 17(6):322-328. doi: 10.1016/j. ejbt.2014.10.001.

33. Kaur G, Srivastava AK, Chand S. Advances in biotechnological production of 1,3-propanediol. Biochem. Eng. J. 2013;64:106-18. doi: 10.1016/j.bej.2012.03.002.

34. Cision PR Newswire. Global 1,4-Butanediol, 2,3-Butanediol and 1,3-Butadiene Markets are Expected to reach 2,357.3 kilo tons, 74.4 kilo tons and 14,799.3 kilo tons respectively in 2018: Transparency Market Research. Albany (NY); 2012.

35. Qin J, Xiao Z, Ma C, Xie N, Liu P, Xu P. Production of 2,3-Butanediol by Klebsiella Pneumoniae Using Glucose and Ammonium Phosphate. Chinese J. Chem. Eng. 2006;14(1):132-6.

36. Garg SK, Jain A. Fermentative production of 2,3-butanediol: a review. Bior. Technology. 1995;51(2-3):103-9.

37. Mariotto JR. Produção de acetoína e 2,3-butanodiol por Bacillus polymyxa Produção de acetoína e 2,3-butanodiol por Bacillus polymyxa [dissertação]. Florianópolis: Universidade Federal de Santa Catarina; 2007. 77 p.

38. Celińska E, Grajek, W. Biotechnological production of 2,3-butanediol-current state and prospects. Biotechnol. Adv. 2009;27(6):715-25. doi: 10.1016/j.biotechadv.2009.05.002.

39. Rossio T. Produção de 2,3-butanodiol a partir de glicerol por Klebsiella oxytoca ATCC8724 [dissertação]. Caxias do Sul: Universidade de Caxias do Sul; 2014.

40. Silva GP, Contiero J, Ávila Neto PM, Lima CJB. 1,3-Propanediol: production, applications and biotechnological potential. Quím. Nova. 2014;37(3):527-34. Doi: 10.1016/j.cattod.2014.05.016.

Data da submissão: 05 de setembro de 2017 Avaliado em: 27 de outubro de 2017 (AVALIADOR A) Avaliado em: 08 de outubro de 2017 (AVALIADOR B) Aceito em: 28 de novembro de 2017 